\title{
What Do People Think They're Doing? Action Identification and Human Behavior
}

\author{
Robin R. Vallacher \\ Florida Atlantic University
}

\author{
Daniel M. Wegner \\ Trinity University
}

\begin{abstract}
Issues in the cognitive representation and control of action are broached from the perspective of action identification theory. This theory holds that any action can be identified in many ways, ranging from low-level identities that specify how the action is performed to high-level identities that signify why or with what effect the action is performed. The level of identification most likely to be adopted by an actor is said to be dictated by processes reflecting a trade-off between concerns for comprehensive action understanding and effective action maintenance. This means that the actor is always sensitive to contextual cues to higher levels of identification but moves to lower levels of identification if the action proves difficult to maintain with higher level identities in mind. These respective processes are documented empirically, as is their coordinated interplay in promoting a level of prepotent identification that matches the upper limits of the actor's capacity to perform the action. The implications of this analysis are developed for action stability, the psychology of performance impairment, personal versus situational causation, and the behavioral bases of self-understanding.
\end{abstract}

People always seem to be doing something. They also seem to be quite adept at identifying what they are doing. What is less clear is how these two observations relate to one another. The theory of action identification (Vallacher \& Wegner, 1985; Wegner \& Vallacher, 1986) is explicitly concerned with this issue. At the heart of the theory are three interacting processes that specify a causal interdependence between what people are doing and what they think they are doing. Through a delineation of these processes, we hope to reveal how action constrains one's identification of action and, in turn, how action identification exerts a selecting and guiding force in subsequent action. The proposed causal interdependence between action and action identification proves useful in understanding a host of issues in human psychology that center on the mental control of action. These issues are thus discussed in detail, with attention given in each case to the points of contact between our analysis and prior conceptualizations. We begin by reviewing the background and principles of the theory.

\section{Cognition and Action}

That people can think about what they do is hardly a controversial idea in psychology. The suggestion, however, that specifiable causal links exist between cognitive representations of action and overt behavior is greeted with skepticism in certain quarters. This skepticism is fueled in part by people's capacity

The research reported in this article was supported in part by Grant BNS 78-26380 from the National Science Foundation.

We wish to thank Roya Ayman, Susan Frank, Toni Giuliano, Lawrence Messé, Thomas Monson, James Pennebaker, and four anonymous reviewers for their helpful comments on an earlier draft.

Correspondence concerning this article should be addressed to Robin R. Vallacher, Department of Psychology, Florida Atlantic University, Boca Raton, Florida 33431. for seemingly unbounded constructions of behavior. As philosophers have long noted, any segment of behavior can be consciously identified in many different ways (Anscombe, 1957; Austin, 1961; Danto, 1963; Goldman, 1970; Ryle, 1949; Wittgenstein, 1953). Something as simple as "meeting someone," for instance, could be recognized by anyone with an even mildly active mental life as "being social," "exchanging pleasantries," "learning about someone new," "revealing one's personality," or even "uttering words." But while representations of action admit to considerable variability and seem subject to noteworthy change from moment to moment, behavior seems to follow a more constrained path, often exhibiting a press toward completion in the face of situational forces, biological needs, and reinforcement contingencies. Thus, as interesting as cognitive representations may be in their own right, they are considered by many to operate independently of the causal mechanisms promoting overt action.

Many psychologists, of course, balk at the notion that cognitive representations of action are mere epiphenomena, with no necessary mapping onto specific overt behavioral events. Those who have addressed this issue explicitly, however, commonly advocate only a limited perspective on the link between cognitive representations and overt behavior. Thus, some commentators have suggested that behavior dynamics are primary, with representations of action arising after the fact, or at best, concurrently with the action. This reflective connection finds explicit expression in such otherwise distinct theories as self-perception theory (Bem, 1972) and psychoanalysis (Freud, 1914/1960). In self-perception theory, the true cause of behavior is some stimulus in the action setting; if the actor does not recognize the stimulus as causal, he or she casts about for other likely causal candidates, even inventing inner dispositions if a plausible external cause cannot be found. In classic Freudian theory, meanwhile, the true cause of action is some unconscious motive striving for expression in even the most mundane of everyday settings. 
Cognitive representations are said to arise after the fact in an attempt to justify or make sense of what was done. Because the true motive is too painful to acknowledge, moreover, the person's post hoc cognitions are, by definition, considered inaccurate.

Other systems stress what might be called the intent connection. In this perspective, cognitive representations of action function as templates for subsequent overt behavior. James's (1890) analysis of ideomotor action, for instance, holds that an idea of action tends to produce the action unless something intervenes to prevent it. This is readily apparent in the case of simple physical movements; to move a finger, one simply thinks about doing so. Not surprisingly, then, the intent connection provides a reasonable summary statement regarding contemporary work on the cognitive control of basic movements (e.g., Adams, 1971; Norman \& Shallice, 1980; Rosenbaum, Kenny, \& Derr, 1983; Schmidt, 1975). With respect to actions of significant duration or importance in people's lives, however, the role of cognitive representations of action in guiding action is less established. What little is known about the cognition-action link in the context of meaningful behavior has been inferred from work in cognitive behavior therapy (e.g., Meichenbaum, 1977); decision making (e.g., Kahneman, Slovic, \& Tversky, 1982); and traditional social-psychological attitude research (e.g., Azjen \& Fishbein, 1977). A direct analysis of how people think about their most far-reaching and consequential actions, and how such thoughts may affect the nature of these actions, is thus missing in contemporary psychology.

A compelling case can be made for both the reflective and intent connections. People do seem to develop representations of their action after the fact, but they also seem capable of planning and directing their action in accord with their cognitive representations. What is needed, then, is a system that provides for integration of these two prototypical cognition-action links, specifying the conditions under which one or the other is likely to occur. This is the task of action identification theory. The theory holds that the relationship between cognitive representations and overt behavior is not unidirectional, but cyclical. Through the intent connection, cognitive representations generate action, and through the reflective connection, new representations of what one is doing can emerge to set the stage for a revised intent connection. In this way, people sometimes are led to maintain a course of action over an extended period of time and on other occasions are led to show dramatic changes in behavior from one moment to the next.

\section{Action Identification Theory}

The essence of the theory is that the identification of one's action, though highly variable in principle, is ultimately constrained by reality. Through the interplay of three processes, each framed as a principle of the theory, people are said to gravitate toward an identification of action that proves effective in maintaining the action. In this section, we present these principles and show their coordinated operation in determining action identification. In the sections to follow, we develop specific determinants of action identification that derive from this analysis and develop the implications of the theory for recurring issues in psychology.

\section{Levels of Identification}

Fundamental to the theory is the recognition that the various identifications for an action do not exist as a random assemblage of unrelated elements. Instead, act identities bear systematic relations to one another in an organized cognitive representation of the action-the action's identity structure. An identity structure is essentially a hierarchical arrangement of an action's various identities. Lower level identities in this hierarchy convey the details or specifics of the action and so indicate how the action is done. Higher level identities convey a more general understanding of the action, indicating why the action is done or what its effects and implications are. Relative to low-level identities, higher level identities tend to be less movement defined and more abstract and to provide a more comprehensive understanding of the action. Identification level is a relative concept, of course, and so whether a given act identity is considered a means or an end, a detail or an implication, depends on the act identity with which it is compared.

The distinction between relatively low- and high-level identities is communicated in everyday language when people indicate that one performs one act identity by performing another (Goldman, 1970). Thus, one sees if someone is home by pushing a doorbell, and one pushes a doorbell by moving a finger. Although these three act identities all pertain to the same act, they exist at different levels in a cognitive hierarchy by virtue of their perceived functional asymmetry. "Seeing if someone is home" occupies the highest level, "pushing a doorbell" the next highest, and "moving a finger" the lowest level. Our research has confirmed that people appreciate the notion of an asymmetric $b y$ relation and can use this relational property to distinguish among act identities (Vallacher, Wegner, Bordieri, \& Wenzlaff, 1981).

\section{Theoretical Principles}

The differences between low- and high-level identities, when considered in conjunction with the three principles of the theory, indicate how the "uncertain act" is resolved realistically by people in everyday life. The first principle holds that action is maintained with respect to its prepotent identity. This principle acknowledges the mental control of action that is reflected in a broad spectrum of theoretical traditions (e.g., Carver \& Scheier, 1981; James, 1890; Luria, 1961; Miller, Galanter, \& Pribram, 1960; Powers, 1973; Schank \& Abelson, 1977; Vygotsky, 1962). Thus, people have in mind a certain idea of what they are doing or want to do and use this prepotent identity as a frame of reference for implementing the action, monitoring its occurrence, and reflecting on its attainment. Because act identities exist at different levels, this principle also holds that people maintain action at different levels. A person may set out simply to "move a finger," for instance, and monitor subsequent action to see whether this intention has been fulfilled, or the person may set out to "dial the phone" (a higher level identity) or "call home" (a yet higher level identity), and monitor the attainment of whichever identity is prepotent.

This principle is useful for understanding instances of action stability, the maintenance of a given action over time and actoss circumstances. Thus, as long as a particular act identity is pre- 
potent, it provides direction for action in the service of identity attainment. Stability is an important and noteworthy feature of human action, of course, but so is the potential for change and apparent inconsistency. The second and third principles represent two basic processes underlying the manifestation of such change.

The second principle holds that when both a lower and $a$ higher level act identity are available, there is a tendency for the higher level identity to become prepotent. The idea here is simply that people are always sensitive to the larger meanings, effects, and implications of what they are doing. This tendency is reflected, implicitly or explicitly, in a variety of psychological systems. Learning under reinforcement contingencies (e.g., Skinner, 1953), the mastery of skilled action (e.g., Bruner, 1970; Bryan \& Harter, 1899; Kimble \& Perlmuter, 1970), Gestalt principles of perception (e.g., Koffka, 1935), even the existentialists' focus on the "search for meaning" (e.g., Frankl, 1963)_all of these seemingly distinct dynamics have in common the notion that act representations expand to encompass broader effects and meanings. In learning, a relatively basic act expands to incorporate the reinforcing effects of the act; in the development of mastery, discrete acts become automated and integrated into a larger action unit; in Gestalt psychology, parts become unified to produce a whole; and in existentialism, patterns discerned in distinct actions become the basis for new awareness of what one is doing and who one is.

Much of the research on action identification to date has focused on the emergence of higher level identities in accordance with the second principle (Wegner, Vallacher, Kiersted, \& Dizadji, 1986; Wegner, Vallacher, Macomber, Wood, \& Arps, 1984). This research confirms that any time a person has only a low-level understanding of what he or she is doing, there is a readiness to accept any higher level identity made available by the context surrounding the action and that this emergent identity can promote wholly new courses of action. In a study by Wegner et al. (1986, Experiment 1), for instance, subjects who identified the act of "participating in an experiment" in terms of its details were found to be more susceptible to a suggestion that they were either "behaving altruistically" (e.g., helping the experimenter) or "behaving selfishly" (e.g., earning extra credits). These subjects, moreover, chose to participate in subsequent activities that were consistent with their emergent understanding. In another study (Wegner et al., 1986, Experiment 2), subjects were presented with bogus personality feedback indicating that they were either cooperative or competitive. In comparison with subjects who had initially described their behavior for analysis at a comprehensive (high) level, those who described their behavior at a detailed (low) level were more accepting of the feedback and more likely to volunteer for future activities consistent with the feedback.

If this were the only mechanism by which identifications of action showed change, people's mental life might indeed be one of fantasy, with little relation to overt behavior. Thus, a person could come to look upon "maintaining eye contact" as "winning trust," "throwing dice" as "winning money," or even "sitting with my legs crossed while watching TV" as "controlling the outcome of the Super Bowl." While these identities could well make sense at the time of their emergence, they may have a tenuous relation at best to any subsequent behavior, no matter how much the person thought he or she was enacting them. The accumulation of high-level identities through coincidence or chance, or through more standard avenues of emergence such as environmental cues and social feedback processes, could charge even the simplest act with unconstrained significance, leaving the actor "buried in thought" (Tolman, 1932) and allowing only occasional contact with the world of real behavior.

Action identification is brought back to reality through a process specified in the theory's third principle: When an action cannot be maintained in terms of its prepotent identity, there is a tendency for a lower level identity to become prepotent. The idea here is simply that people must sometimes concern themselves with the how-to aspects of action in order to perform the action. A person may set out to "change a light bulb," for instance, but unless that action is automated to an appreciable extent, he or she may have to consciously plan and monitor such things as "grasping the bulb at its widest point," "turning the bulb counterclockwise," and so forth. Even if the action has become automated through repeated experience, its details might still become prepotent if the action were to be disrupted by some means. The light bulb, for instance, may prove to be stuck in its socket, in which case the person might give conscious consideration to "grasping" and "turning" at the temporary expense of the higher level "changing" identity. In the attempt to maintain action under one identity, one must often abandon that identity in favor of more performable identities. So, although a person may be inclined to adopt any of a host of higher level identities for an action, these identities dissipate in short order if they prove to be ineffective guides to subsequent action. The potential for flights of fancy that is inherent in the second principle is unlikely to represent a serious problem for most people, then, because of the reality orientation inherent in the third principle.

Research to date has documented the potential for movement to lower levels of identification in the face of high-level disruption. In a study by Wegner et al. (1984, Experiment 2), for instance, experienced coffee drinkers were asked to drink coffee from one of two rather different cups-a normal cup and an unwieldly cup weighing approximately $0.5 \mathrm{~kg}$. Upon completion of this act, subjects were asked to rate how well each of 30 identities for coffee drinking described what they had done. Subjects in the normal cup condition tended to give relatively strong endorsement to identities such as "getting energized" or "promoting my caffeine habit." Subjects in the unwieldly cup condition, for whom the act of drinking proved difficult to do, tended to give relatively strong endorsement to identities at a substantially lower level, such as "drinking a liquid," "swallowing," and "lifting a cup to my lips." Presumably, these subjects could not "energize themselves" or "promote their caffeine habit" with only these identities in mind. Instead, to accomplish the act at all, they had to think about the mechanics of coffee drinking, and this low-level orientation became prepotent, temporarily at least, in lieu of their accustomed way of thinking about the act.

A similar effect was obtained by Wegner, Connally, Shearer, and Vallacher (1983) in a study involving the act of eating. All subjects were invited to "eat Cheetos." But whereas some subjects were to eat the Cheetos in the usual manner (with their hands), other subjects were asked to retrieve the Cheetos with a 
pair of chopsticks. This latter technique proved difficult to do, and when asked subsequently what they had done, subjects in the chopsticks condition tended to eschew identities like "eating," "reducing hunger," and "getting nutrition" in favor of lower level identities like "chewing," "swallowing," "putting food in my mouth," and "moving my hands." Subjects in the nonchopsticks condition, meanwhile, gave weaker endorsement to these lower level identities and correspondingly stronger endorsement to the various higher level identities ("reducing hunger," "getting nutrition," etc.). As in the coffee drinking study, then, difficulty in enacting an action normally identified at high level promoted a movement to a lower level of identification.

The three principles of the theory work together in such a way that maintainable identifications of one's action ultimately develop. There is a constant press for higher level understanding and control of action, but this press is countermanded by movement to lower levels of identification when the higher level identities cannot be enacted automatically. Over time and repeated action, the oscillations reflected in this dynamic interplay begin to flatten out, and the person converges on an identity at a particular level that enables him or her to perform the action up to his or her capacity. For any given action performed by a particular person, then, the range of potential understanding is likely to be notably restricted in the service of effective action control.

\section{Determinants of Identification Level}

The principles of the theory suggest in a general way how people come to an unambiguous understanding of what they are doing. To enable predictions regarding specific instances of action identification, however, it is necessary to relate the processes outlined in the theory to factors amenable to operational definition. Three sets of such factors would seem to play especially pivotal roles in promoting unequivocal act knowledge: the context in which the action takes place, the action's diffculty, and the person's experience with the action. Each of these influences on prepotent identification is discussed in turn.

\section{Action Context}

Knowing only the physical movements involved in an action, it is difficult to know what was done. As Danto (1963) has observed, without knowledge of circumstances or events outside the action itself, one is left with only the most rudimentary of identities, or what he called a "basic act." It is through sensitivity to contextual cues that movement becomes represented in terms of its causal effects, conventional interpretations, and the like. What appears to be the same action can therefore be identified in vastly different ways depending on the relative salience of various cues to identification provided by the action's context. "Solving a math puzzle," for instance, might be thought of primarily as "keeping track of numbers" or "making mental calculations" in one setting (e.g., the privacy of one's home) but as "showing my math skill" or "trying not to embarrass myself" in another (e.g., a testing situation).

Context often imparts a relatively high level of identification to action. It is difficult to look upon what one is doing as simply a set of movements when there are circumstantial and social cues as to the labels, effects, and implications of these move- ments. This idea, of course, is inherent in the second principle of the theory and has been confirmed in the research on action emergence alluded to earlier (Wegner et al., 1986; Wegner et al., 1984). Thus, unless one already has a clear sense of the larger meaning of what one is doing, there is a readiness to embrace new identifications of action provided by the context in which one is acting.

At the same time, certain kinds of contextual factors can move a person to relatively low levels of identification. Foremost among these factors are those that serve to disrupt action (e.g., Wegner et al., 1983; Wegner et al., 1984, Experiment 2). Thus, an awkward cup can make one think of the details associated with "drinking," and poor transmission quality during a phone call can change the prepotent identity of one's action from "exchanging gossip" to "making myself heard" or "speaking loudly and clearly." Beyond their potential for disrupting action, some situations offer ambiguous or inconsistent cues as to the meaning or effect of what one is doing. In social situations, for instance, it is often hard to discern whether one is creating a good or bad impression, demonstrating wit or poor taste, and so on. The only thing one knows for sure is that one is "talking," "gesturing," and the like. Uncertainty regarding the effects and implications of one's behavior is especially likely in novel settings lacking familiar cues to higher level meaning. A person in such a setting may be prone to accept any higher level identities made available, but until these identities are provided the person is left with only a rudimentary sense of what he or she is doing. Finally, in some contexts a person may be asked to monitor the details of his or her behavior as it is being enacted and in this way experience a lower level of identification than would normally be the case (e.g., Wegner et al., 1986, Experiment 2; Wegner et al., 1984, Experiment 1).

\section{Action Difficulty}

Contextual cues to identities at different levels are probably present in the majority of everyday circumstances. The novelty of a particular setting could make one sensitive to the lower level features of what one is doing, for example, while the evaluative pressures in the setting might render higher level identities (e.g., "impress others," "show my skill") prepotent. For this reason, context alone is rarely an unambiguous guide to a person's prepotent level of identification. Our analysis suggests a far less equivocal guide to identification level-the action's personal level of difficulty.

Some things are harder to do than others. A person may set out to "push a doorbell," for example, and find that this identity is easily enacted. The person may then try to "sell a set of encyclopedias" to the person answering the doorbell-a somewhat more formidable task. As the action begins to unfold, the person finds it necessary to suspend the "selling" identity in favor of more specific identities such as "sounding sincere," "appearing respectful yet confident," and "raising the issue of responsible parenthood." Each of these identities, in turn, may prove somewhat difficult to maintain, in which case the person will probably begin to think in terms of yet lower level identities. "Sounding sincere," for example, may require "furrowing one's eyebrows," "making continuous eye contact," and "talking in a slow and deliberate tone of voice." 
This example illustrates a very basic point: The more difficult or disruption-prone an action is under a given identity, the greater the likelihood that it will be enacted under a lower level identity. Disruption potential, in turn, is traceable to more specific aspects of action. Five aspects in particular seem important and so are likely to establish identification level prepotency. We refer to these key aspects of action as maintenance indicators, because they indicate the level at which an action should be identified for optimal performance. Thus, an action under a particular identity can be scaled with respect to its relative difficulty of enactment, familiarity, complexity (variety of means or subacts), enactment time, and learning time (amount of time it takes to learn to do the action well). Compared to the act of "selling encyclopedias," for instance, "pushing a doorbell" is relatively easy: familiar for most people, can be enacted in only a few ways, occupies a short interval of time, and takes little time to learn. An action should be identified at a relatively high as opposed to low level to the extent that it shares these indicator values; an action with indicator values at the opposite ends of these dimensions, meanwhile, is likely to be maintained with lower level identities in mind.

To see whether such relationships exist, Wegner and Vallacher (1983) arranged for a variety of everyday actions to be rated with respect to each of the five maintenance indicators and for these actions to be reidentified at either a lower or a higher level, according to the subjects' personal preference. A sample of 274 undergraduates (155 women, 119 men) was asked to choose low- versus high-level reidentifications for each of 25 actions. ${ }^{1}$ These actions were chosen to represent a spectrum of the things people do in daily life and included such actions as "pushing a doorbell," "voting," "paying the rent," and "reading." Each was presented along with two alternative identities, one lower and one higher in level, and subjects were to indicate which alternative best expressed their personal understanding of the action. Because our concern centered on the level at which people would attempt to maintain a given action, we avoided high-level alternatives that were likely to be seen as unanticipated or unpleasant consequences of the action.

By tracking the proportion of high-level choices for a given action across subjects, an average identification level value was obtained for the action (possible range $=0-1$ ). These values were normally distributed, although the mean value was fairly high level (.66). Actions identified at a relatively low level included "having a cavity filled," "taking a test," and "resisting temptation." Actions identified at a relatively high level included "reading," "locking a door," and "pushing a doorbell."

Another sample ( 35 women, 15 men) was asked to rate the 25 action stems on 5-point scales for difficulty, familiarity, complexity, enactment time, and learning time. We then intercorrelated all of the ratings with identification level across the 25 actions. Table 1 presents the results of this analysis. It is clear that an action's typical level of identification does indeed covary with each of the indicators. As predicted, an action was reidentified at a high rather than low level to the extent that it was seen as easy to do, familiar, performable in a few ways, short in duration, and requiring little time to learn well. Table 1 also reveals strong intercorrelations among the five indicators. Hence, they were summed (after reverse scoring familiarity) to create an overall index of maintenance difficulty. This index, which
Table 1

Intercorrelations of Maintenance Indicators

and Identification Level

\begin{tabular}{lrrrrr}
\hline \multicolumn{1}{c}{ Variable } & 1 & 2 & 3 & 4 & 5 \\
\hline 1. Difficulty & - & & & & \\
2. Familiarity & -.53 & - & & & \\
3. Complexity & .40 & .21 & $-\bar{c}$ & & \\
4. Enactment time & .77 & -.25 & .71 & - & \\
5. Learning time & .85 & -.37 & .60 & .91 & $-\overline{27}$ \\
6. Identification level & -.48 & .29 & -.20 & -.26 & -.27 \\
\hline
\end{tabular}

Note. The correlations are computed across 25 actions and are based on the sample mean for each rating on each action. The mean rating across actions for each of the maintenance indicators is based on an $n$ of 50; the mean identification level across actions is based on an $n$ of 274.

proved reliable (Cronbach's alpha $=.83$ ), was significantly correlated with identification level across the action set, $r(25)=$ $-.39, p<.02$; overall, difficult-to-maintain actions were identified at lower levels.

These data should not be taken as evidence that for any action only one level of identification is likely to assume prepotence. Indeed, if that were the case, the "uncertain act" would not have emerged as a philosophical problem in the first place, nor would people be so adept at volunteering alternative depictions of what they are doing. There does seem to be something like a central tendency across actors in an action's identification level, a tendency that reflects a concomitant central tendency in the action's maintenance indicators. This much would be predicted by a categorical judgment model (e.g., Brown, 1958; Rosch, 1973, 1978). Against this normative backdrop, though, a certain degree of variability in both identification level and indicator values is to be expected. Thus, an action may be difficult in one setting or for one person but easy in another setting or for someone else, and these differences in personal act difficulty should be reflected in the respective identities that assume prepotence.

\section{Action Experience}

To a large extent, variability in an action's difficulty is determined by the person's degree of experience with the action. Several distinct traditions in psychology have converged on the notion that with increasing action experience there is a corresponding increase in action automaticity (e.g., Fitts \& Posner, 1967; Kimble \& Perlmuter, 1970; Langer, 1978; Weiss, 1939). Presumably, as one gains familiarity with an action's lower level components, these components become integrated or "chunked" into larger action units, and it is these larger units that become the basis for conscious control of the action. An accomplished pianist, for instance, does not give conscious consideration to finger movements, key selection, and pedal pushing (see, e.g., Sudnow, 1978). In short, with increments in action

\footnotetext{
'The action set was assembled initially for the construction of an instrument to assess individual differences in characteristic level of action identification (Vallacher, Wegner, \& Cook, 1982).
} 
experience, there is an increment in action automaticity and personal ability, and a consequent reduction in the individual's personal difficulty in performing the action.

According to the theory, these changes should prompt corresponding changes in level of prepotent identification. Thus, when low-level identities are unfamiliar and relatively difficult to maintain, emergence to higher level identities is effectively blocked; the third principle (movement to lower level prepotence) in a sense holds sway over the second principle (movement to higher level prepotence). As the lower level identities become mastered with increasing experience, however, there is a readiness to appreciate higher level identities and attempt maintenance with respect to them; the second principle becomes ascendant over the third principle. As these high-level identities then become mastered, the person is in a position to maintain the action with respect to yet higher level identities, and so on, in a progression that leads to both greater proficiency and more comprehensive understanding of the action. No matter how proficient one is at an action, then, there is always a way to identify what one is doing so as to rekindle the challenge of effective maintenance.

The progression from low to high level identity prepotence with increments in action experience is demonstrated in an investigation by Vallacher, Wegner, and Frederick (1981). We asked a group of subjects $(N=116)$ to tell us what they do when they engage in each of five distinct actions-tennis, karate, piano playing, writing, and the video game Space Invaders. ${ }^{2} \mathrm{Ac}-$ tion identification questionnaires were provided for this purpose, each consisting of 36-38 one-sentence descriptions of the action under consideration. Subjects were to rate (on 7-point scales) how well each identity statement described the action for them. Factor analyses of these ratings revealed a low-level factor for each action as well as several higher level factors. A low-level index was computed for each action that represented a subject's summed ratings of identities loading on the low-level factor relative to his or her summed ratings across all factors.

The low-level index was then correlated with a self-report measure of subjects' experience with the action. The correlations were negative for every action ( $r$ ranged from -.17 to -.56), reaching statistical significance in three of the five cases. A similar pattern was observed when the low-level index was correlated with subjects' self-reported proficiency at the action (rs ranged from -.19 to -.45 ). So, for actions as diverse as video games and piano playing, there is a waning of low-level prepotence as the actor gains familiarity and proficiency with the action. In rendering actions progressively more familiar, more automatic, and otherwise easier to do, experience enables action to be understood in terms that transcend the action's mechanistic underpinnings and highlight instead its potential meanings, effects, and implications.

\section{Identification Level and Behavior}

The principles of the theory suggest that there is always conscious mental control of action. Across diverse domains of action, and despite wide natural variation in action context, action difficulty, and personal expertise, the immediate precursor to action is a mental representation of what one is doing. The representations that guide action, however, admit to consider- able variation in their level of identification, and this variability has implications for the form that action control is likely to take. In this section, we outline the basic differences in action control associated with relatively low versus high levels of identification and develop the implications of these differences for the psychology of performance impairment, personal versus situational causation, and the relationship between self-concept and behavior.

\section{Levels of Action Control}

Variation in identification level holds two key implications for action control. The first concerns action stability. When an action is undertaken with only a relatively low-level identity in mind, there is a tendency to accept a higher level identity made available by the action's context, and this new understanding of what one is doing can serve to change dramatically the course of one's subsequent behavior. A person who is simply "riding a bike," for example, may come to look upon the action as "seeing the neighborhood," "unwinding from a hard day," or "getting exercise," depending on the contextual cues surrounding the act. Each of these higher level identities is associated with an array of lower level identities besides bike riding and so could transform the act entirely. "Seeing the neighborhood," for instance, might result in parking the bike and walking in order to get a better look; "unwinding" might lead the person home and to the liquor cabinet.

High-level identification, meanwhile, lends itself to action stability because it effectively shields the person against the emergence of alternative identities that could substantially change the nature of subsequent action. In essence, a person with a relatively high level understanding already knows what he or she is doing and thus is less primed to accept other understandings at the same level provided by the context surrounding the action. Such understanding allows people to maintain a course of action in the face of changing conditions and with the passage of time. The bike rider who is "getting exercise," for instance, is likely to persist in this action regardless of new possibilities for action that might become available.

The second implication of variation in identification level concerns action flexibility. When an action is maintained at a relatively high level, its physical manifestation may appear to change markedly from one occasion to the next. The bike rider "getting exercise," for instance, may disembark from the bike to do something that looks quite different (e.g., jogging), although phenomenologically he or she is still doing the same thing. Lower level identities, on the other hand, come closer to specifying the physical movements involved in the action and so admit to far less variability in their mode of enactment. "Riding a bike" encompasses such lower level acts as speeding up, slowing

\footnotetext{
${ }^{2}$ The action identification tendencies of those who indicated they had never performed the action and of those who were in the initial stages of action involvement were aiso explored in this study. Because the perspectives of such outsiders and beginners are independent of the act maintenance considerations that influence prepotency on the part of act performers, the data relevant to these perspectives are not considered here. For a presentation and theoretical consideration of these data, see Vallacher and Wegner (1985, Chap. 7).
} 
down, and turning corners, for example, but unlike "getting exercise," it does not encompass getting off the bike to jog. Thus, with increments in identification level, there is a corresponding increase in the range of interchangeable means available for maintaining the action, and this imparts a noteworthy degree of flexibility to action.

When an action is controlled with respect to a relatively highlevel identity, then, changes in its lower level manifestations over time do not necessarily signal inconsistency. Indeed, a certain amount of flexibility is often necessary to maintain a broadly conceived action. Consistency and flexibility, however, take on different meanings when viewed in terms of low-level action control. If consistency exists at all for an action identified at a low level, it is because of stable environmental cues that keep the person mindful of the task at hand. Flexibility, meanwhile, reflects impulsive emergence to new courses of action when the environmental cues change. An action controlled at a low level, then, cannot be consistent and flexible at the same time; which orientation predominates depends on the constancy of the action context.

\section{Performance Impairment}

In view of these differences between low- and high-level identification, it is tempting to view higher level states as preferable. High-level understanding seems to come closer to capturing the essence of knowing what one is doing, and the stability and flexibility of action associated with the high-level state sound preferable to the inconsistency versus rigidity characterizing lower levels of identification. High levels of identification can prove to be a mixed blessing, however. Particularly in contexts where behavior is highly scripted (Schank \& Abelson, 1977), the inattention to detail and nuance that comes with high-level action control can appear to be "mindless" rather than thoughtful (Langer, 1978). In terms of our account, of course, mindless action is a somewhat misleading term. The principles of the theory suggest that well-learned, automated acts are performed with a representation of the act in mind, just as difficult, unfamiliar acts are. If the person does not seem to know what he or she is doing - that is, if he or she appears to be acting mindlessly - it is because the observer (or psychologist, for that matter) is identifying the action at a different level.

Nonetheless, it is possible for action control to be attempted at too high a level. Our data demonstrate, of course, that people tend to gravitate toward a level of identification that is warranted by the action's difficulty (Wegner \& Vallacher, 1983) and to embrace higher levels of identification only when their experience readies them for such understanding (Vallacher, Wegner, \& Frederick, 1981). This tendency should not be taken to mean that people always think about what they are doing in the "right" way, however. People choke under pressure, suffer from evaluation apprehension, get distracted, lose concentration, revert to old habits, worry about failure, get overconfident, and in other ways manage to approach action with a dysfunctional mental set (e.g., Baumeister, 1984; Berlyne, 1963; Carver \& Scheier, 1981; Norman \& Shallice, 1980; Reason \& Mycielska, 1982; Rosenberg, 1965; Sarason, 1972; Schwartz, 1982; Wine, 1971). The convergence on a maintainable identification level is clearly a delicate process, one that is sensitive to various forms of interference.

The potential for interference reflects the simple fact that an action's prepotent identity is shaped by the context in which the action occurs. Thus, an environmental press toward higher level identities for one's action could serve to impair performance if the action's maintenance indicators warranted relatively low-level identification. The person might move to lower levels in accord with the third principle, but the cues to higher level meanings may not be sufficiently ignored to allow appropriate attention to detail. Indeed, because the low-level state sensitizes one to higher level identities, the movement to low level in the face of high-level failure could ensure that the person would keep mindful of the disruptive higher level identities. In support of this reasoning, several lines of research have converged on the notion that social and environmental pressures to do well, engendered by such things as the promise of reward or threat of punishment, competition, audience evaluation, and the like, tend to facilitate performance on simple or welllearned tasks but to impair performance on difficult or unfamiliar tasks (e.g., Berlyne, 1963; Cofer \& Appley, 1964; Fitts \& Posner, 1967; Zajonc, 1965). Such factors are similar in that they emphasize the higher level meanings and effects of one's action.

At the same time, action control can be attempted at too low a level. Just as difficult or unfamiliar action can be impaired by high-level identities made available by the action's context, so too can easy or familiar action be disrupted when the context calls attention to the lower level aspects of one's action. Indeed, the idea that overlearned performance can be debilitated by explicit attention to mechanistic aspects of action represents another well-established empirical generalization regarding human performance (e.g., Bryan \& Harter, 1899; Kimble \& Perlmuter, 1970; Langer \& Imber, 1979). Thus, for an expert typist, attention to key selection and finger movements can produce errors and disrupt rhythm, just as an experienced driver's attention to pedal pushing and steering wheel rotation can introduce awkwardness into driving. Not only are low-level identities unnecessary for easy-to-maintain action, then, but their prepotence can also serve to disintegrate an action normally integrated with respect to a higher level understanding. An action that flows smoothly when enacted at high level can become choppy when enacted at low level.

The context of action thus holds potential for impairing action performance, pulling the person away from an identification level determined by personal action difficulty. The manifestation of this potential, however, is probably tempered by people's self-selection of settings in which to act. The random assignment of people to conditions in psychological research provides valuable insight into the effects of audience pressure, competition, and the like on performance quality, of course, but it almost certainly overestimates the frequency of performance impairment in daily life. More often than not, people seek out new and more demanding contexts for action only when their experience and skill readies them for higher level challenges. Thus, whereas an inexperienced tennis player is likely to shy away from a tennis court surrounded by observers, a more proficient player might actively seek out a context that renders "demonstrating skill" or "impressing an audience" prepotent 
at the expense of more elementary act identities. More generally, when a given act identity becomes relatively easy to maintain, the person is in a preemergence state and thus is sensitive to new action contexts that would impart higher level understanding to the action. This sort of self-selection could ensure that most people will undertake action with respect to an optimal level of identification much of the time.

\section{Personal Versus Situational Causation}

In discussions of action control, it is common to distinguish between personal and situational causation. This purported dichotomy lies at the heart of a continuing controversy in personality and social psychology concerning the determinants of behavior (see, e.g., Bowers, 1973; Epstein, 1979, 1983; Mischel, 1968; Mischel \& Peake, 1982), and judging by theories of causal attribution, it is of burning interest to laypersons as well (Heider, 1958; Jones \& Davis, 1965; Kelley, 1967). The basic issue seems simple enough: When a person does something, is it because of his or her personal penchant for behaving that way or because of some aspect of the action context that would elicit that behavior from most anyone? Phrased more concretely, does behavior reflect a manifestation of personality traits, selfconceived values, and other inner qualities, or a response to rewards, punishments, and other inducements to action in the situation?

Strictly speaking, of course, the proximate cause of behavior is always personal, inasmuch as behavior is initiated and guided by a mental representation of the behavior. The issue thus becomes one of locating the source of people's prepotent act identities in their idiosyncratic identity structures versus the context surrounding the action. Conceptually, the resolution of this issue involves a straightforward extension of the argument concerning identification level and action control. When a person undertakes an action with a relatively low-level identity in mind, he or she is especially sensitive to contextual information concerning the larger meaning and significance of the act. As this information is afforded by the situation, the person's prepotent act identity - and hence, his or her subsequent behaviormay be seen as a reflection of situational factors. On the other hand, when a person enters an action context with a relatively high-level identity for his or her action and is able to maintain this identity throughout the period of enactment, the person may be said to be acting in accordance with personal rather than situational considerations. Thus, high-level action control is likely to reflect the implementation of one's goals, values, and interests rather than reactivity to situational cues.

Though straightforward conceptually, the person-versus-situation issue can prove to be quite tricky empirically. The problem inheres in the uncertainty of action. Because an action is open to different identifications, it may be difficult for an observer (or a psychologist) to determine whether a person is acting in accordance with his or her goals, concerns, and so forth, or whether he or she instead is responding to situational cues. The criterion of cross-situational consistency is commonly invoked to make this determination. Thus, if the person behaves the same way from one context to the next, it can be assumed that he or she is acting out of personal "causes," but if his or her behavior covaries with contextual factors, it can be assumed that he or she is responding to presses in the immediate situation.

Given the flexibility associated with high-level action control, this criterion of personal versus situational causation is clearly inadequate. The person might "act sociably," for instance, by "joking around" on one occasion and by "discussing the world's problems" on another. To someone not privy to the high-level identity operating in both instances, these behaviors might seem independent or even inconsistent with respect to a trait dimension like humorous versus serious. By the same token, an observer might note cross-situational consistency when none exists from the person's point of view. The person might help an elderly person cross the street, for example, and sometime later assist someone of the opposite sex in retrieving a dropped armload of books. Though both actions seem like "being helpful" to the observer, the person may have performed them under vastly different high-level identities-"show respect for the elderly" and "strike up a friendship."

A related criterion for determining personal versus situational causation concerns the uniqueness of a person's behavior vis-à-vis others in a given situation. According to this criterion, which finds expression in influential models of causal attribution (e.g., Jones \& Davis, 1965; Kelley, 1967), the person is said to be acting in accordance with inner determinants (traits, values, etc.) to the extent that his or her behavior deviates from the behavior typical of people in that situation. Conversely, if his or her behavior matches the observer's expectancy for behavior in that situation (e.g., if the behavior has high consensus across actors [Kelley, 1967] or is high in social desirability [Jones \& Davis, 1965]), the person is said to be responding to forces in the situation.

The problem noted for the cross-situational consistency criterion is clearly applicable here as well. Assume, for example, that the person is observed "discussing sports," and that others in that situation are observed doing the same thing. By the within-situation variability criterion, the person is said to be responding to the situation. "Discussing sports," however, is only one of many possible identities for the person's behavior, any one of which may have been the prepotent identity. Thus, the person may have entered the situation with only a low-level identity like "talking" in mind, in which case the social cues to higher level identities assumed prominence; the person begins "discussing sports" like everyone else, thereby revealing situational causation. On the other hand, the person may have approached the setting with a higher level identity in mind, such as "make a good impression," "demonstrate my command of facts," or "put others at ease." The particular high-level identity guiding the person's behavior may surface regularly in his or her identity structure, reflecting stable and idiosyncratic orientations toward behavior-the hallmark of personal causation.

This reasoning helps to illuminate a purported difference between actors and observers in their respective attribution tendencies. Jones and Nisbett (1971) argued that observers are inclined toward personal causes in explaining the actor's behavior, whereas the actor is more inclined toward invoking situational causes. The fact that this difference has been demonstrated in laboratory experiments (e.g., Storms, 1973) and in rather unusual natural settings (West, Gunn, \& Chernicky, 1975) is not too surprising. Given the unfamiliarity of such contexts for ac- 
tion, the actor subject could well have only a rudimentary understanding of what he or she is doing. Situational cues to higher level meaning are thus attended to, so when queried later the actor quite reasonably points to features of the setting as being causal. The observer, meanwhile, is not privy to the actor's uncertainty and may conclude that the actor is behaving in accordance with an overall plan, goal, or self-conceived personality trait. By this reasoning, the actor-observer difference should dissipate in settings that are familiar for the actor. Because familiar settings are associated with equally familiar plans and anticipated effects in the actor's identity structure, the actor is likely to view his or her behavior as a manifestation of these personal high-level identities rather than as a reaction to situational forces. In support of this idea, there is evidence that actors do indeed ascribe their behavior to personal rather than situational causes in familiar situations (Monson \& Snyder, 1977).

This analysis of actor-observer differences in attribution is speculative, of course, but it does underscore our central point concerning commonly invoked criteria of personal versus situational causation. Without knowledge of a person's phenomenal organization of action, it is difficult for an observer (lay or professional) to determine whether the person's behavior reflects personal considerations that surface regularly in different contexts or responsiveness to contextual cues that provide meaning for an action undertaken at a relatively low level. In this light, it is hardly surprising that the trait approach to personality has met with only limited success (see, e.g., Mischel, 1968). Although people differ reliably in their scores on tests designed to measure trait variation, these scores typically do a poor job of predicting behavior. Thus, a person might have a high-level identity (e.g., "being helpful") that regularly assumes prepotence, and this identity may provide personal integration for actions that seem diverse or even inconsistent when identified at lower levels (e.g., "giving constructive criticism to a friend," "providing uniformly positive feedback to an insecure acquaintance"). To the person, then, many different actions are seen as expressions of the same thing. But to a psychologist, employing act identities derived from personal experience or past empirical evidence, these actions may be grouped in ways that depart dramatically from the person's own organization. As a result, the person is seen as acting inconsistently with his or her selfreported trait.

More generally, the complex nature of identity structures suggests that the search for traitlike consistency, even in an idiographic sense (Bem \& Allen, 1974), is unlikely to be successful. Even if we know the person's phenomenal organization of action, there is no guarantee that every instance of a particular low-level identity will be an expression of the same high-level identity. On one occasion, "giving constructive criticism" may be reached via the higher level identity of "being helpful"; on another occasion, "giving constructive criticism" might be reached via the higher level of "demonstrating intelligence." Our research reveals that there is a strong potential for overlapping organizations in identity structures (Vallacher, Wegner, Bordieri, \& Wenzlaff, 1981), and this potential should caution us against thinking of high-level act identities as personality traits in the usual sense. Each high-level act identity in the person's overall structure serves as a possible mode of action orga- nization for the person and thus indicates what the person might be doing across a range of lower level identities.

This does not mean that the person-versus-situation causation issue is intractable. To the contrary, our analysis of the determinants of low-level versus high-level identification enables a priori prediction of whether the person will look to contextual cues for deciding what to do or instead will act in accordance with high-level identities that he or she brings to the situation. To make such predictions, one must know the action's maintenance difficulty (i.e., its complexity, unfamiliarity, and so on); the person's experience with the action domain; and the salience of contextual cues to identification.

\section{Self-Concept and Behavior}

To an appreciable extent, knowledge of what one is like is gleaned from knowledge of what one is doing, has done, or is inclined to do. Were it not for the self-defining potential of action, it is unlikely that people would expend so much effort justifying what they have done, rationalizing their misdeeds and failures, claiming credit for success, and attempting to discredit certain kinds of social feedback regarding their behavioral propensities (Shrauger \& Schoeneman, 1979; Snyder, Stephan, \& Rosenfield, 1978; Swann, 1983). As we have seen, however, this simple input for self-conception-action-is inherently uncertain, open to a wide variety of prepotent identifications. The principles by which people reduce this uncertainty and come to an unambiguous knowledge of their action would thus seem to have natural relevance to dynamics of self-conception.

The relevance of action identification principles to self-conception begins with the recognition that act identities at high levels hold greater potential for defining one's self than do lower level act identities. "Creating a piece of art," for instance, conveys more information about the person behind the action than does a lower level identity like "moving a paintbrush." "Demonstrating one's artistic competence" or "expressing one's world view," in turn, conveys more information about the actor than does "creating a piece of art." While identities at lower levels are devoid of self-defining significance, higher level identities are practically synonymous with such significance. It is not surprising, then, that assessment of people's self-conceptions typically involves self-ratings along dimensions reflective of behavioral propensities (Wylie, 1979). In this research tradition, people are said to think of themselves in terms of such highlevel action dimensions as cooperative versus competitive, dominant versus submissive, and friendly versus unfriendly.

In this light, it is interesting to consider two contrasting perspectives on the relationship between self-concept and behavior. One perspective holds that a person's self-concept admits to remarkable variability and is open to continual modification and reshaping as a result of action (e.g., Gergen, 1977; Shrauger \& Schoeneman, 1979). Processes of self-perception (e.g., Bem, 1972; Freedman \& Fraser, 1966) and social feedback (e.g., Mead, 1934; Miller, Brickman, \& Bolen, 1975) are commonly invoked to account for this relationship between self-concept and behavior. The other perspective holds that a person's selfconcept is stable over time and across settings, providing a consistent frame of reference for action (e.g., Block, 1981; Costa \& McCrae, 1980). Indeed, when a self-view is threatened by 
contradictory social feedback, the person is said to be especially inclined to act in accordance with his or her self-conceived values and behavioral propensities (e.g., Swann, 1983).

Action identification theory suggests that both perspectives are valid, but under different circumstances. Whether the selfconcept appears to be stable or malleable depends on the level of identification that is prepotent for a person when he or she encounters a situation conducive to self-perception or social feedback. If the person's identity is at a high enough level, he or she should show stability, resisting new information afforded by the physical and social environment concerning his or her personal attributes and capacities. Under conditions that promote a relatively low-level identification, however, contextual information regarding one's self is likely to be accepted, for it provides emergent understanding in accordance with the theory's second principle (i.e., movement to higher level prepotence).

Evidence in support of this analysis is provided in a study by Wegner et al. (1986, Experiment 2), alluded to earlier. Subjects in that study were provided with bogus personality feedback indicating that they were either cooperative or competitive. The ostensible data for the personality feedback consisted of a description generated by subjects of a recent social interaction between them and someone else. Subjects were to generate five one-sentence descriptions of their behavior in this interaction and enter each into a computer console. Half of the subjects were instructed to describe their behavior in relatively low-level terms (e.g., particular comments, questions, and gestures). The other subjects were asked to describe their behavior in higher level terms (e.g., opinions expressed, values communicated, and personality traits demonstrated). Subsequent coding of their descriptions by trained raters showed this manipulation of identification level to be effective. The computer then delivered an ostensible personality analysis telling subjects that they were either very cooperative or very competitive.

After examining the feedback, subjects were asked to judge the validity of the feedback and the usefulness of the program that generated it. As predicted, subjects led to think about their behavior at lower levels expressed greater belief in the bogus feedback and greater confidence in the program than did those who were led to conceptualize their behavior in high-level terms. Subjects also completed a questionnaire assessing their self-image with respect to 20 personality trait dimensions, including cooperativeness and competitiveness. Results showed that subjects in the low-level condition rated themselves consistently with the ostensible feedback; those who received cooperativeness feedback rated themselves as more cooperative, whereas those who received competitiveness feedback rated themselves as more competitive. Subjects in the high-level condition, meanwhile, did not rate themselves in line with the feedback they had received. This same pattern was observed when subjects were subsequently given a chance to participate in future research projects that involved cooperative or competitive behavior on their part. Subjects in the low-level condition opted for a cooperative task if they had received cooperative feedback but opted for a competitive task if they had received competitive feedback. Subjects in the high-level condition were not influenced by the feedback in their choice of future activities.

Beyond confirming the emergence phenomenon specified by the second principle of the theory, these results help to clarify when a self-concept is likely to be stable, serving to initiate and maintain action, and when it is likely to be malleable, undergoing transformation as a result of action. It is not surprising, for example, that self-concepts appear to be highly malleable and responsive to social feedback under laboratory conditions (Gergen, 1977). Subjects in such research are commonly called upon to do something unfamiliar (e.g., converse with a stranger over headphones) or difficult (e.g., solve anagrams) and to do so in an unusual setting (a lab). Such a state of affairs is conducive to low-level identification and thus should make subjects sensitive to contextual cues regarding the larger meaning of their action. It is inevitable, then, that subjects should appear responsive to social feedback delivered by the experimenter or an experimental confederate or that they should come to "discover" what they are like in accordance with self-perception dynamics.

In the more routine and familiar contexts pervading everyday life, however, changes in self-concept via social feedback and self-discovery should be less frequently observed (e.g., Swann \& Hill, 1982), because people are likely to have a relatively highlevel identity for what they are doing. If self-concept change is observed in daily life, it is because a crucial precondition for emergence has been established-a movement to low-level identification. People are occasionally asked to recount the details of something they have done, for example, and in this way might experience a lower level of identification than would normally be the case (as in Wegner et al., 1986, Experiment 2). Interruption of ongoing action also occurs with a certain degree of regularity in daily life, and this too can promote relatively low-level identification (e.g., Wegner et al., 1984, Experiment 2). These events, and no doubt many others that promote lowlevel identification, make people vulnerable to the information afforded by the contexts surrounding their action.

\section{Summary and Conclusions}

Action identification theory is not the first perspective to propose explicit links between thinking and doing. Almost a century ago, James (1890) proposed that goal-directed physical movement is preceded by a mental representation of such movement. This emphasis on mental representations of action has provided the touchstone for virtually every perspective on mind and action advanced since James's time. It is common in this theoretical tradition to posit a hierarchy-or sometimes a heterarchy - of representations to account for complex goal-directed action (e.g., Carver \& Scheier, 1981; Gallistel, 1980; Lashley, 1951; Miller, Galanter, \& Pribram, 1960; Newell, 1978; Norman, 1981; Powers, 1973; Schank \& Abelson, 1977). The action's goal or purpose is said to occupy the highest level in such hierarchies, whereas subordinate levels serve to subdivide this goal into progressively more concrete representations, until a level is reached that specifies the actual movements to be undertaken.

Like other approaches, action identification theory emphasizes the mental representation of action and the organization of such representations in a hierarchical structure. The principles of the theory, however, tend to spawn identity structures that lack the symmetry and closure normally associated with hierarchies. Principle 1 holds that people maintain action in 
accord with their prepotent identity for the action, Principle 2 holds that people embrace higher level identities when these become available, and Principle 3 holds that failure to maintain action under one identity will move people to a lower level of identification. The coordinated interplay of these principles promotes action understanding that is dynamic, self-correcting, and always open to change. Every time an action is performed, there is the potential for new act identities, higher or lower in level, to be incorporated into one's identity structure. Thus, as is common in hierarchical models, a given high-level identity can come to subsume a number of different lower level identities. But by the same token, the same low-level identity can, in different contexts, generate widely divergent higher level identities. These high-level identities, meanwhile, may be related to each other only by virtue of their mutual linkages to the lower level identity and thus will operate as independent meanings for the action. As a result, a person's identity structure for a domain of action is likely to be highly complex, consisting of multiple, overlapping hierarchies.

The complexity of identity structures imparts remarkable flexibility and individuality to the mental control of action. Indeed, without knowledge of a person's phenomenal organization of action, it may be difficult for an observer to determine whether the person is maintaining a particular course of action over time or, instead, is doing different things. Among those commentators who are sensitive to this feature of mental representations, the typical response has been to challenge the alleged lawfulness of human action (e.g., Gauld \& Shotter, 1977; Gergen, 1978, 1985; Harré \& Secord, 1972). In this view, not only can people identify their action in many different ways and thus chart idiosyncratic and flexible courses of action, the phenomenological nature of this process renders it opaque to traditional modes of scientific inquiry. After all, if action is open to different identifications, how can a researcher be sure that he or she has hit upon the "real" identity guiding a subject's behavior in an experimental setting? A discipline that cannot even come to agreement on its basic unit of analysis would seem to be a discipline based on shifting sands at best and, at worst, doomed to theoretical dead ends and contradictions.

The theory we have advanced attempts to reconcile the seeming conflict between unbounded consciousness on the one hand and bounded, lawful behavior on the other. Thus, although the identification of action appears to be open-ended, limited only by our constructive and labeling capacities, the particular identity that assumes prepotence is ultimately constrained by reality. Among the factors that restrict the range of viable identities are various contextual cues surrounding the action, the personal difficulty of the action, and the person's experience with the action. Each of these determinants of identification level, in turn, can be cast in terms of yet more specific factors. Contextual cues, for example, include such things as situational novelty versus familiarity, audience presence versus absence, and the promise of rewards versus the threat of punishment. The degree of action difficulty, meanwhile, can be specified through knowledge of the action's maintenance indicators (e.g., its unfamiliarity, complexity, and enactment time). And personal action experience can be gleaned from noting a person's history of involvement with the action. These factors operate in accor- dance with the three principles of the theory to dictate how a person will attempt to control action in a given circumstance.

The variation in prepotent identification level that results from the operation of these factors has extensive implications for important realms of personal functioning. Thus, a person controlling an act with relatively low-level identities in mind is prone toward inconsistent, perhaps even impulsive, behavior and is highly sensitive to social feedback and other contextual cues to higher level meaning. The person controlling action at a relatively high level, meanwhile, can behave flexibly with respect to lower level identities while maintaining a broader goal or purpose and is effectively shielded against new high-level identities afforded by the social and physical environment. Performance impairment also can be understood in terms of variation in identification level. An action is performed effectively to the extent that the person's prepotent level of identification is in line with the action's maintenance indicators.

Finally, we wish to emphasize that the dynamic, open-ended nature of action identification processes allows for marked changes in people's identity structures throughout their lives. Every time an action is undertaken, the identities made available by the action's context, the antecedent identity that set the action in motion, and other identities that exist in the person's accumulated identity structure, compete for prepotence. Only those identities that prove to be effective guides to action win this competition-and stand ready to provide direction for action in the future. Given the multiplicity of contexts in which people act and the likelihood that such contexts are encountered with different frequencies at different points in one's life, the repeated emergence of new act identities is an ever-present possibility. When all is said and done, perhaps the only enduring characteristic of a person's identity structure is its potential for change. Yet, no matter how idiosyncratic such changes are, they are ultimately driven by desires common to everyone-to know what one is doing and to do what one can.

\section{References}

Adams, J. A. (1971). A closed-loop theory of motor learning. Journal of Motor Behavior, 3, 111-119.

Anscombe, G. E. M. (1957). Intention. Oxford, England: Blackwell.

Austin, J. L. (1961). Philosophical papers. London: Oxford University Press.

Azjen, I., \& Fishbein, M. (1977). Attitude-behavior relations: A theoretical analysis and review of empirical research. Psychological Bulletin, 84, 888-918.

Baumeister, R. (1984). Choking under pressure: Self-consciousness and the paradoxical effects of incentives on skilled performance. Journal of Personality and Social Psychology, 46, 610-620.

Bem, D. J. (1972). Self-perception theory. In L. Berkowitz (Ed.), Advances in experimental social psychology (Vol. 6, pp. 1-62). New York: Academic Press.

Bem, D. J., \& Allen, A. (1974). On predicting some of the people some of the time: The search for cross-situational consistencies in behavior. Psychological Review, 81, 506-520.

Berlyne, D. E. (1963). Motivational problems raised by exploratory and epistemic behavior. In S. Koch (Ed.), Psychology: A study of a science (Vol. 5, pp. 284-364). New York: McGraw-Hill.

Block, J. (1981). Some enduring and consequential structures of personality. In A. I. Rabin et al. (Eds.), Further explorations in personality (pp. 27-43). New York: Wiley. 
Bowers, K. S. (1973). Situationism in psychology: An analysis and a critique. Psychological Review, 90, 307-336.

Brown, R. W. (1958). How shall a thing be called? Psychological Review, $65,14-21$.

Bruner, J. S. (1970). The growth and structure of skill. In K. Connolly (Ed.), Mechanisms of motor skill development (pp. 88-103). New York: Academic Press.

Bryan, W. L., \& Harter, L. (1899). Studies on the telegraphic language: The acquisition of a hierarchy of habits. Psychological Review, 6 , 345-378.

Carver, C. S., \& Scheier, M. F. (1981). Attention and self-regulation: A control-theory approach to human behavior. New York: Springer-Verlag.

Cofer, C. N., \& Appley, M. H. (1964). Motivation: Theory and research. New York: Wiley.

Costa, P. T., Jr., \& McCrae, R. R. (1980). Still stable after all these years: Personality as a key to some issues in adulthood and old age. In P. B. Baltes \& O. G. Brim, Jr. (Eds.), Life span development and behavior (Vol. 3, pp. 66-103). New York: Academic Press.

Danto, A. (1963). What we can do. Journal of Philosophy, 40, 435-445.

Epstein, S. (1979). The stability of behavior. I. On predicting most of the people much of the time. Journal of Personality and Social Psye chology, 37, 1097-1126.

Epstein, S. (1983). The stability of confusion: A reply to Mischel and Peake. Psychological Review, 90, 179-184.

Fitts, P. M., \& Posner, M. I. (1967). Human performance. Belmont, CA: Brooks/Cole.

Frankl, V. E. (1963). Man's search for meaning. New York: Washington Square Press.

Freedman, J. L., \& Fraser, S. C. (1966). Compliance without pressure: The foot-in-the-door technique. Journal of Personality and Social Psychology, 4, 195-202.

Freud, S. (1960). The psychopathology of everyday life. New York: Norton. (Original work published 1914)

Gallistel, C. R. (1980). The organization of action. Hillsdale, NJ: Erlbaum.

Gauld, A., \& Shotter, J. (1977). Human action and its psychological investigation. London: Routledge \& Kegan Paul.

Gergen, K. J. (1977). The social construction of self-knowledge. In T. Mischel (Ed.), The self: Psychological and philosophical issues (pp. 139-169). Totowa, NJ: Rowman \& Littlefield.

Gergen, K. J. (1978). Toward generative theory. Journal of Personality and Social Psychology, 36, 1344-1360.

Gergen, K. J. (1985). The social constructionist movement in modern psychology. American Psychologist, 40, 266-275.

Goldman, A. I. (1970). A theory of human action. Princeton, NJ: Princeton University Press.

Harré, R., \& Secord, P. F. (1972). The explanation of social behaviour. Oxford, England: Blackwell.

Heider, F. (1958). The psychology of interpersonal relations. New York: Wiley.

James, W. (1890). Principles of psychology. New York: Holt.

Jones, E. E., \& Davis, K. E. (1965). From acts to dispositions: The attribution process in person perception. In L. Berkowitz (Ed.), Advances in experimental social psychology (Vol. 2, pp. 219-266). New York: Academic Press.

Jones, E. E., \& Nisbett, R. E. (1971). The actor and observer: Divergent perceptions of the causes of behavior. In E. E. Jones, D. E. Kanouse, H. H. Kelley, R. E. Nisbett, S. Valins, \& B. Weiner (Eds.), Attribution: Perceiving the causes of behavior (pp. 79-94). Morristown, NJ: General Learning Press.

Kahneman, D., Slovic, P., \& Tversky, A. (Eds.). (1982). Judgment under uncertainty: Heuristics and biases. New York: Cambridge University Press.
Kelley, H. H. (1967). Attribution in social psychology. Nebraska Symposium on Motivation, 15, 192-238.

Kimble, G. A., \& Perlmuter, L. C. (1970). The problem of volition. Psychological Review, 77, 361-384.

Koffka, K. (1935). The principles of gestalt psychology. New York: Harcourt.

Langer, E. J. (1978). Rethinking the role of thought in social interaction. In J. Harvey, W. Ickes, \& R. F. Kidd (Eds.), New directions in attribution research (Vol. 2, pp. 35-58). Hillsdale, NJ: Erlbaum.

Langer, E. J., \& Imber, L. G. (1979). When practice makes imperfect: Debilitating effects of overlearning. Joumal of Personality and Social Psychology, 37, 2014-2024.

Lashley, K. (1951). The problem of serial order in behavior. In L. A. Jeffress (Ed.), Cerebral mechanisms in behavior, the Hixon symposium (pp. 112-136). New York: Wiley.

Luria, A. R. (1961). The role of speech in the regulation of normal and abnormal behavior (J. Tizard, Trans.). New York: Liveright.

Mead, G. H. (1934). Mind, self, and society. Chicago: University of Chicago Press.

Meichenbaum, D. (1977). Cognitive-behavior modification. New York: Plenum Press.

Miller, G. A., Galanter, E., \& Pribram, K. H. (1960). Plans and the structure of behavior. New York: Holt.

Miller, R. L., Brickman, P., \& Bolen, D. (1975). Attribution versus persuasion as a means of modifying behavior. Journal of Personality and Social Psychology, 31, 430-441.

Mischel, W. (1968). Personality and assessment. New York: Wiley.

Mischel, W., \& Peake, P. K. (1982). Beyond déjà vu in the search for cross-situational consistency. Psychological Review, 89, 730-755.

Monson, T. C., \& Snyder, M. (1977). Actors, observers, and the attribution process: Toward a reconceptualization. Journal of Experimental Social Psychology, 13, 89-111.

Newell, K. M. (1978). Some issues on action plans. In G. E. Stelmach (Ed.), Information processing in motor control and learning (pp. 4154). New York: Academic Press.

Norman, D. A. (1981). Categorization of action slips. Psychological Review, $88,1-15$

Norman, D. A., \& Shallice, T. (1980). Attention to action: Willed and automatic control of behavior (Tech. Rep. No. 8006). San Diego: Center for Human Information Processing, University of California.

Powers, W. T. (1973). Behavior: The control of perception. Chicago: Aldine.

Reason, J., \& Mycielska, K. (1982). Absent-minded? The psychology of mental lapses and everyday errors. Englewood Cliffs, NJ: PrenticeHall.

Rosch, E. H. (1973). Natural categories. Cognitive psychology, 4, 328350.

Rosch, E. H. (1978). Principles of categorization. In E. Rosch \& B. B. Lloyd (Eds.), Cognition and categorization (pp. 27-48). Hillsdale, NJ: Erlbaum.

Rosenbaum, D. A., Kenny, S. B., \& Derr, M. A. (1983). Hierarchical control of rapid movement sequences. Journal of Experimental Psychology: Human Perception and Performance, 9, 86-102.

Rosenberg, M. J. (1965). When dissonance fails: On eliminating evaluation apprehension from attitude measurement. Journal of Personality and Social Psychology, 1, 28-42.

Ryle, G. (1949). The concept of mind. London: Hutchinson.

Sarason, I. G. (1972). Experimental approaches to test anxiety: Attention and the uses of information. In C. D. Spielberger (Ed.), Anxiety: Current trends in theory and research (Vol. 2, 383-403). New York: Academic Press.

Schank, R. C., \& Abelson, R. P. (1977). Scripts, plans, goals, and understanding. Hillsdale, NJ: Erlbaum. 
Schmidt, R. (1975). A schema theory of discrete motor learning. Psychological Review, 82, 225-260.

Schwartz, B. (1982). Reinforcement-induced behavioral stereotypy: How not to teach people to discover rules. Journal of Experimental Psychology: General, 111, 23-59.

Shrauger, J. S., \& Schoeneman, T. J. (1979). Symbolic interactionist view of self-concept: Through the looking glass darkly. Psychological Bulletin, 86, 549-573.

Skinner, B. F. (1953). Science and human behavior. New York: Macmillan.

Snyder, M. L., Stephan, W. G., \& Rosenfield, D. (1978). Attributional egotism. In J. H. Harvey, W. Ickes, \& R. F. Kidd (Eds.), New directions in attribution research (Vol. 2, pp. 91-117). Hillsdale, NJ: Erlbaum.

Storms, M. D. (1973). Videotape and the attribution process: Reversing actors' and observers' points of view. Joumal of Personality and Social Psychology, 27, 165-175.

Sudnow, D. (1978). Ways of the hand. New York: Harper \& Row.

Swann, W. B., Jr. (1983). Self-verification: Bringing social reality into harmony with the self. In J. Suls \& A. G. Greenwald (Eds.), Social psychological perspectives on the self (Vol. 2, pp. 33-66). Hillsdale, NJ: Erlbaum.

Swann, W. B., Jr., \& Hill, C. A. (1982). When our identities are mistaken: Reaffirming self-conceptions through social interaction. Journal of Personality and Social Psychology, 43, 59-66.

Tolman, E. C. (1932). Purposive behavior in animals and men. New York: Appleton-Century-Crofts.

Vallacher, R. R., \& Wegner, D. M. (1985). A theory of action identification. Hillsdale, NJ: Erlbaum.

Vallacher, R. R., Wegner, D. M., Bordieri, J., \& Wenzlaff, R. (1981). [Models of act identity structures]. Unpublished research data.

Vallacher, R. R., Wegner, D. M., \& Cook, C. (1982). [Construction of the behavior identification form]. Unpublished research data.
Vallacher, R. R., Wegner, D. M., \& Frederick, J. (1981). [Experience and the identification of action]. Unpublished research data.

Vygotsky, L. S. (1962). Thought and language. Cambridge, MA: MIT Press.

Wegner, D. M., Connally, D., Shearer, D., \& Vallacher, R. R. (1983). [Disruption and identifications of the act of eating]. Unpublished research data.

Wegner, D. M., \& Vallacher, R. R. (1983). [Action identification level and maintenance indicator ratings]. Unpublished research data.

Wegner, D. M., \& Vallacher, R. R. (1986). Action identification. In R. M. Sorrentino \& E. T. Higgins (Eds.), Handbook of motivation and cognition: Foundations of social behavior (pp. 550-582). New York: Guilford.

Wegner, D. M., Vallacher, R. R., Kiersted, G., \& Dizadji, D. (1986). Action identification in the emergence of social behavior. Social Cognition, 4, 18-38.

Wegner, D. M., Vallacher, R. R., Macomber, G., Wood, R., \& Arps, K. (1984). The emergence of action. Joumal of Personality and Social Psychology, 46, 269-279.

Weiss, P. (1939). Principles of development. New York: Holt.

West, S. B., Gunn, S. P., \& Chernicky, P. (1975). Ubiquitous Watergate: An attributional analysis. Journal of Personality and Social Psychology, 32, 55-65.

Wine, J. D. (1971). Test anxiety and the direction of attention. Psychological Bulletin, 76, 92-104.

Wittgenstein, L. (1953). Philosophical investigations. Oxford, England: Blackwell.

Wylie, R. C. (1979). The self-concept (Vol. 2). Lincoln: University of Nebraska Press.

Zajonc, R. B. (1965). Social facilitation. Science, 149, 269-274.

Received October 31, 1985

Revision received January 13, 1986 